\section{Women editors: change comes from focused action}

SIR - Your News story "Societies spurn women editors" (Nature 440, 974-975; 2006) raises valid concerns about the lack of women in leadership positions in many scientific societies and on many editorial boards. The Society for Glycobiology, of which I am currently president, has a membership of chemists, biochemists and biologists. The majority of our members are male, but the society takes a direct route to ensure participation of women in all our activities.

Our leaders and members, as well as the editorial board of our journal, Glycobiology, actively encourage the election of women to leadership positions. Women currently occupy three of the six positions on the society's board of directors. Three of the past ten society presidents have been women, and women make up about $20 \%$ of the editorial board. The programme committee has ensured participation of women as platform speakers and session chairs at our annual national meeting. In addition, our policy is to include short talks by two or three junior scientists in every session of the meeting, to allow exposure of their work in a national forum - a policy that helps junior scientists of both genders.

I cite these figures to highlight how a concerted effort to be inclusive can yield meaningful change in leadership positions. Focused, explicit and determined actions to change the balance of participation by women in scientific societies may be required to effect rapid change, rather than the hope that change will eventually occur over time. Linda G. Baum

Department of Pathology, UCLA School of Medicine, 10833 LeConte Avenue, Los Angeles, California 90095, USA

\section{Women editors: we need more female scientists}

SIR - Your News story "Societies spurn women editors" (Nature 440, 974-975; 2006) suggests that there is ongoing and systematic bias against women for the position of editor of Evolution. As vice-president of the Society for the Study of Evolution and associate editor of Evolution, I strongly believe this is not the case. Several women were identified as potential editors-in-chief of Evolution: women with strong research records, broad visions for the field and wide support. But not one of those approached was interested in the position.

Why are women declining to be considered? In the face of the many obstacles to women in science, those of us who have established successful research careers have done so by learning to say "no". The task of editor-inchief is onerous, time-consuming and largely thankless. Potential candidates recognize that saying "yes" to this particular job comes at an enormous personal cost - to one's research career, students and family.

It is important to recognize that women in science do a disproportionate share of service because of the desire for gender equality on committees. Expecting us to do more is not necessarily in the best interests of women or science. The paucity of female editors points to the need to encourage the scientific careers of women: only when there are more senior women scientists are we likely to see this problem go away.

\section{Sarah P. Otto}

Department of Zoology, University of British Columbia, 6270 University Boulevard, Vancouver, British Columbia V6T 1Z4, Canada

\section{Women editors: nominees turned down Evolution job}

SIR - As president of the Society for the Study of Evolution, I object to the claim that women were not adequately considered for the position of editor-in-chief of the journal Evolution ("Societies spurn women editors" Nature 440, 974-975; 2006). The society is not sexist, nor do we reject women for senior positions. Of the past six presidents, three have been women. Our governing body has eight men and seven women, including our current chief executive and financial officer. Some 42 (29\%) of our associate editors since 1995 have been women, compared with 23\% of our membership.

It is true that we have had only one female editor-in-chief. However, five women were approached about their interest in the position before Mark Rausher was appointed, and all declined. The selection process involved a committee of six instead of three as stipulated in our by-laws, but this widened input and involved more women - including Theresa Markow. She raised no procedural issues until after the new editor-in-chief had been selected, agreed to serve and started to appoint other editors. The officers and council responded promptly to these issues in early 2006, but voted to approve the new editors rather than repeat the search.

Ironically, Markow's resignation deprives evolutionists of a woman at the most senior position in our society.

I must also ask: why has Nature never had a female editor-in-chief?

\section{Don Waller}

Department of Botany, 430 Lincoln Drive,

University of Wisconsin, Madison,

Wisconsin 53706, USA

We stand by our description of the selection procedure - Editor, Nature.

\section{'Referee factor' would reward a vital contribution}

SIR - At a time when academia is increasingly focused on measures of performance, there is no provision for those who referee articles, even though the process is onerous, time-consuming and critical to the advance of science. For the system to be fair, all scientists should be refereeing two to three times as many articles as they submit.

The solution is simple. Some journals already acknowledge referees at the end of each year, but if this process were standardized for all journals, each stating the number of manuscripts seen by individuals, the data could be compiled by a suitable mechanism such as Google Scholar. The results could ultimately be translated into a 'referee factor', consisting of the sum of the impact factors for the respective journals multiplied by the number of articles reviewed. Multiple versions of the same manuscript probably need not be factored in, as the work involved in assessing revisions is considerably less than that for previously unseen contributions. The 'referee factor' could be built into standard assessments of performance, acting as an incentive for people to review manuscripts and otherwise making attitudes apparent.

\section{Rory Wilson}

Biological Sciences, University of Wales Swansea, Singleton Park, Swansea SA2 8PP, Wales, UK

See Nature's web debate on peer review at www. nature.com/nature/peerreview/debate/index.html

\section{Still light-years away from articulating the infinite}

SIR - The Universe may perhaps be infinite, but even to distinguish this from a very large finite Universe would seem to be scientifically impossible. Yet objects such as comet Encke, used to illustrate Peter Coles' book review ("From here to eternity" Nature 441,$285 ;$ 2006), hardly encourage us to consider an infinite universe to be reasonable. Encke is a body in the Solar System, a few light-hours away. In fact, it is one of the closest comets to the Sun.

You might have pictured a distant galactic cluster, such as the Great Wall - perhaps 200-300 million light years away. But even that would be a finite distance, no closer to infinity than a walk across the road. lan Stewart

Mathematics Institute, University of Warwick, Coventry CV4 7AL, UK

Contributions to Correspondence may be submitted to corres@nature.com.They should be signed by no more than three authors; preferably by one. 